\title{
A importância do treinamento da criança com baixa visão, com emprego dos auxílios ópticos, para capacitação educacional: relato de caso
}

\author{
The value of optical aids' training for low vision child education: case report
}

Eduardo Toshio Sato ${ }^{1}$

Celina Tamaki-Castro ${ }^{2}$

Danilo Dimas Monteiro de Castro ${ }^{3}$

\section{RESUMO}

O aprendizado do correto manuseio do auxílio óptico foi treinado: localização, focalização e seguimento com o telescópio de 8x de magnificação. Após essa etapa iniciou-se o aprendizado de cópia da lousa com o auxílio adaptado. Totalizaram-se 17 sessões para a criança receber a prescrição final devido às grandes dificuldades apresentadas pela baixa acentuada das funções visuais.

Descritores: Baixa visão; Recursos audiovisuais; Intervenção precoce (educação); Capacitação; Criança; Pré-escolar; Relatos de casos

\section{INTRODUÇÃ̃O}

A seleção do recurso óptico é sempre uma relação entre o tamanho do campo visual remanescente e o grau de magnificação necessária, e a sua escolha depende principalmente dos objetivos do paciente. Adaptação dos auxílios ópticos requer treinamento e prática das técnicas de utilização nas diferentes atividades ${ }^{(1)}$. O uso desses instrumentos deve fazer parte do programa de treinamento da visão residual, assim como o acompanhamento da adaptação e resultados obtidos ao longo prazo.

\section{RELATO DE CASO}

C.V.L., sexo masculino, 6 anos, natural de São Paulo, escolaridade pré3, foi encaminhado do setor de Neuro-oftalmologia (2006), com diagnóstico de hipertensão intracraniana benigna para reabilitação visual. Apresentou queixa de baixa da acuidade visual acentuada havia dez meses (não progressiva) e fotofobia. A principal atividade prejudicada pela baixa visual foi dificuldade no acompanhamento escolar.

No exame oftalmológico, apresentou à biomicroscopia córnea transparente, câmara anterior ampla, íris e cristalino sem alterações. O exame do fundo de olho mostrou edema do disco óptico em ambos os olhos e no exame de refração foi encontrado $+0,25 \mathrm{DE} \sim-0,50 \mathrm{DC}$ a $175^{\circ}$ no olho direito e $+0,50 \mathrm{DE} \sim-0,50 \mathrm{DC}$ a $85^{\circ}$ no olho esquerdo que não foram corrigidos opticamente. Lentes filtrantes âmbar foram adaptadas devido à fotofobia.

$\mathrm{Na}$ avaliação funcional da visão, apresentou acuidade visual (AV) no olho direito 10/600 e no olho esquerdo movimentos de mão, com alterações centrais no campo visual computadorizado em ambos os olhos (entretanto com resultados não confiáveis devido à má colaboração), dificulda- 
de de distinguir cores primárias, baixa sensibilidade ao contraste e na avaliação da motilidade ocular extrínseca apresentou exotropia de 30 dioptrias prismáticas.

Teste com auxílios ópticos:

- Telescópio monocular de 6x = AV: 10/100

- Telescópio monocular de 8x = AV: 10/40.

Determinado o melhor auxílio óptico, o telescópio de 8x, foram iniciadas sessões de treinamento de manuseio. No primeiro treinamento foram realizados exercícios de:

- Localização: localizar objetos da sala (relógio na parede, figuras, quadros, porta de armário, janelas, objetos coloridos), utilizando o telescópio para familiarizar-se com a diminuição do campo visual;

- Focalização: aprender o manuseio da lente ocular para realizar a focalização da imagem;

- Seguimento: procurar números de 1 a 20 na ordem crescente impressos num pôster colocado a 2 metros.

Devido à grande dificuldade, algumas orientações foram dadas, como permitir aproximar-se do material de trabalho na escola (livro, lousa, cartilha), usar cadernos com pautas refor-
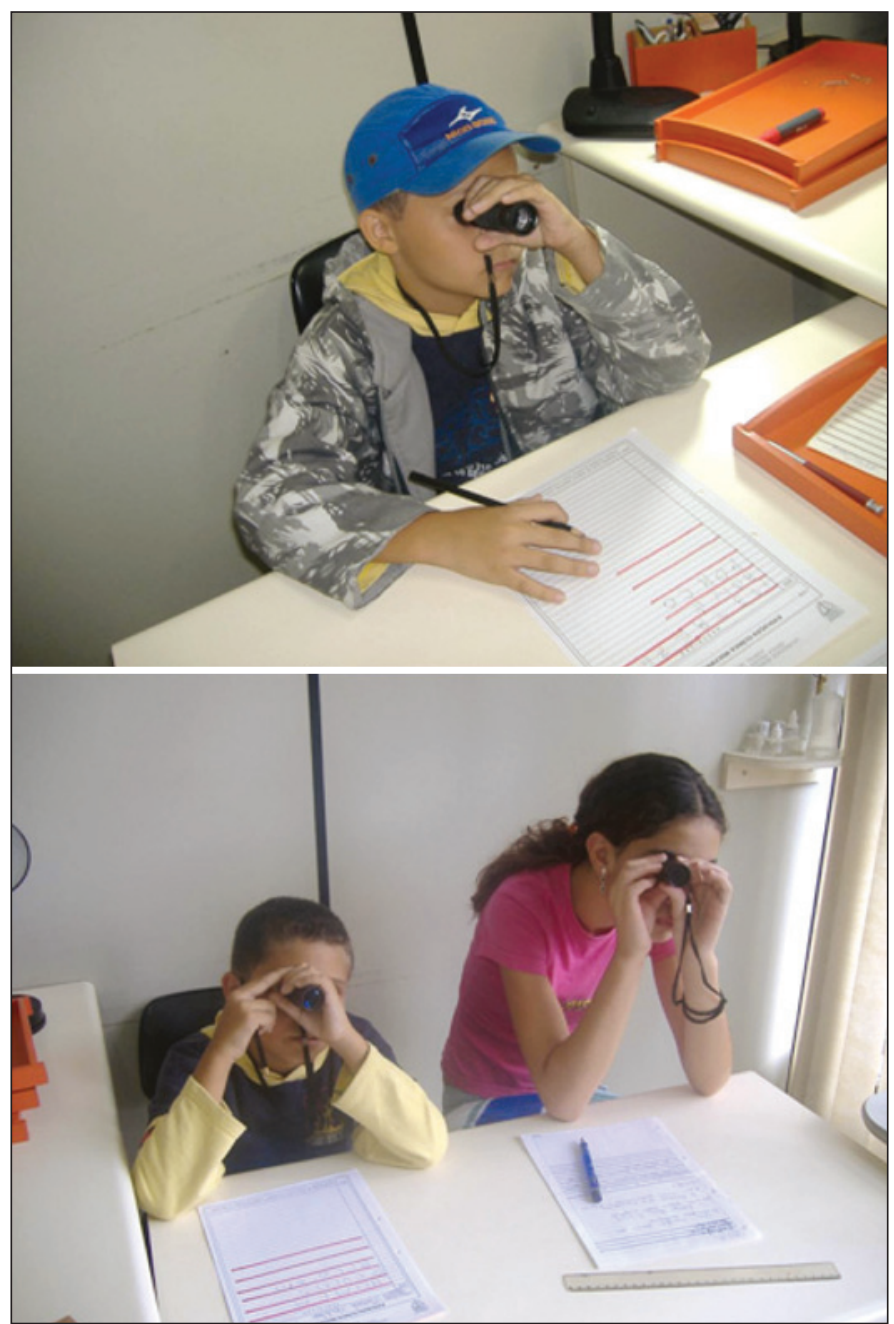

Figura 1 - Sessões de treinamento com o telescópio (cópia de lousa) çadas, canetas de ponta porosa e/ou lápis grafite 6B. E também devido à grande dificuldade no treinamento do seguimento, foi orientado treinamento em casa, exercício de simulação de diminuição de campo visual que o telescópio proporciona, utilizando um "rolinho de papelão" de $5 \mathrm{~cm}$ de diâmetro e $10 \mathrm{~cm}$ de comprimento.

Após cinco sessões de treinamento:

- Ainda apresentava dificuldades em localizar e focalizar;

- Apresentou demora no escaneamento dos números, levando 5 minutos para achar números de 1 a 9 , não conseguindo completar até o 20 devido à fadiga;

- Paralelamente ao exercício de seguimento, foram realizadas tentativas de cópias de frases escritas na lousa (distância de 2 metros);

- Criança desmotivada e desanimada.

Após oito sessões de treinamento, houve melhora na localização e focalização de objetos e figuras para longe. O tempo de escaneamento diminuiu, completando o seguimento total dos números entre 5 e 6 minutos. O seu desempenho melhorou ao realizar sessões de treinamentos em grupo com outras crianças (Figura 1), o que aumentou a sua motivação para realizar cópia de lousa.

Após 15 sessões de treinamento:

- Localização e focalização com facilidade;

- Tempo de escaneamento variou entre 52 segundos e 1 minuto;

- Realizou cópias de lousa com facilidade, mesmo diminuindo o tamanho da letra e a cor do giz (Figura 2).

No total, foram necessárias 17 sessões de treinamento até receber a prescrição final do auxílio de visão subnormal para longe.

\section{DISCUSS ÃO}

O treinamento do manuseio do auxílio óptico tem como objetivo ajudar a criança a usar o seu resíduo visual e pos-

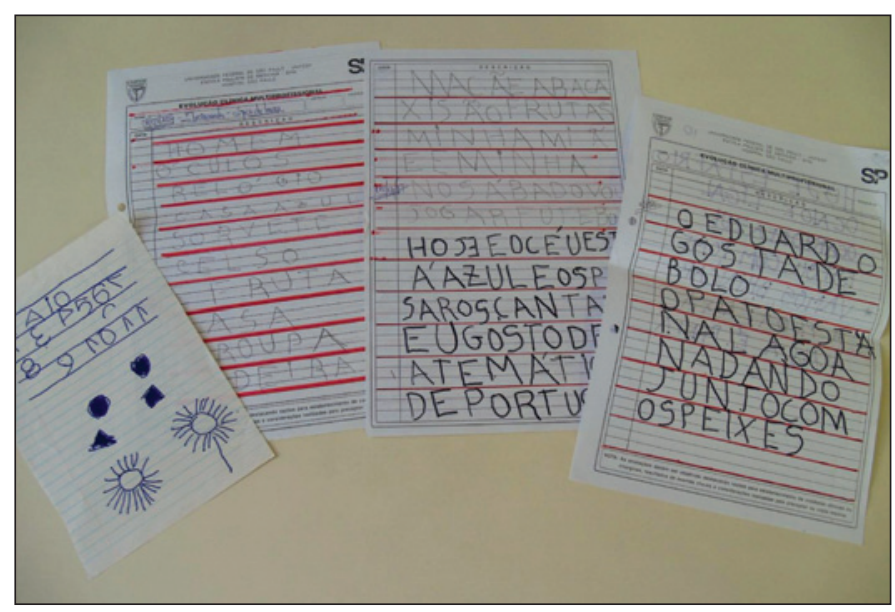

Figura 2 - Cópias realizadas pela criança durante o treinamento com o telescópio de $8 x$ 
284 A importância do treinamento da criança com baixa visão, com emprego dos auxílios ópticos, para capacitação educacional: relato de caso

sibilitar estímulos para que haja melhor desenvolvimento cognitivo $^{(2)}$. Muitas vezes, o treinamento com o telescópio é realizado com crianças em idade pré-escolar ou logo que mostram algum interesse ou desenvolvimento da aptidão (destreza e capacidade de manuseio) ${ }^{(1,3-4)}$. Portanto, o desenvolvimento da capacidade de utilizar eficientemente o recurso óptico a ser prescrito se torna um passo importante da reabilitação visual.

\section{ABSTRACT}

Training of the proper handling of optical devices was performed: location, targeting and tracking with the $8 \mathrm{x}$ magnification telescope. After this step, learning to a copy from a blackboard with the adapted optical aid was initiated. Seventeen sessions were required for the child's final prescription due to severe low vision and loss of visual functions.

Keywords: Vision, low; Audiovisual aids; Early intervention (education); Training; Child; Child, preschool; Case reports

\section{REFERÊNCIAS}

1. Ritchie JP, Sonksen PM, Gouldt E. Low vision aids for preschool children. Dev Med Child Neurol. 1989;31(4):509-19.

2. Teplin SU. Visual impairment in infants and young children. Inf Young Children. 1995;8:18-51.

3. Castro DDM. Visão subnormal. In: Tartarella MB, Tamaki-Castro C. Estimulação visual precoce. Rio de Janeiro: Cultura Médica; 1994. p.94-107.

4. Cox RF, Reimer AM, Verezen CA, Smitsman AW, Vervloed MP, Boonstra FN. Young children's use of a visual aid: an experimental study of the effectiveness of training. Dev Med Child Neurol. 2009;51(6):460-7.

\section{ABD ELETRONNIGD}

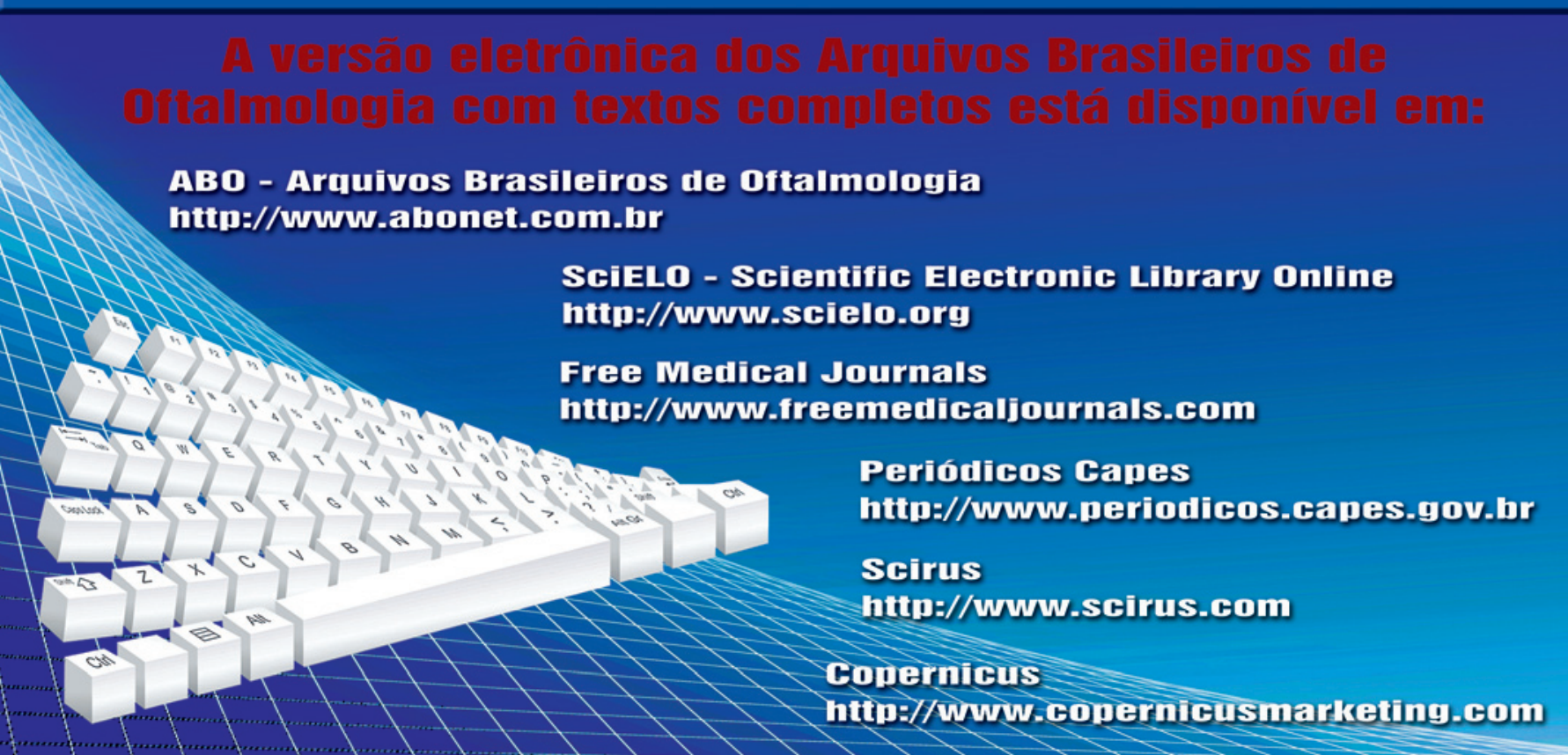

Arq Bras Oftalmol. 2010;73(3):282-4 